\title{
Indoor Environmental Requirements in Green Building
}

\section{in Jordan}

\author{
Mayyadah Fahmi Hussein \\ Department of Interior Design, Faculty of Architect and Art, Petra University, Amman 11196, Jordan
}

\begin{abstract}
The aim of this study is to provide stimulating and comfortable environments for the occupants and minimize the risk of green building related health problems. Researcher has developed a number of assumptions that helps to resolve the research problems, which includes the application of the indoor environmental quality and will highlight the required design standards of it to provide a healthy environment to the houses and chosen AREE (Aqaba residence energy efficiency) as a case study. The theoretical part goes through a brief study to definition of the required design standards which includes eight kinds of issues: indoor environmental quality intents, control of environmental tobacco smoke, control of chemicals contaminants, design well ventilated buildings, provide daylight/view, energy efficient lighting, thermal comfort, consider acoustics and its uses in all the elements of internal spaces. Than we going through the uses of these requirements by using descriptive analytical approach, we chose one case study (AREE). To analyze the uses of their requirements of the indoor environmental quality and we also collect the information about this house from the owner of the AREE, then draw conclusions and list of references.
\end{abstract}

Key words: Indoor environmental quality, green building, Al Aqaba residence.

\section{Introduction}

Energy use in buildings accounts globally for nearly $40 \%$ of global energy consumption and $36 \%$ of total energy-related carbon dioxide emissions [1]. These percentages are almost equally split in two halves between the industrialized countries and the rest of the world [2].

Our buildings use energy in two ways: first, to keep our interior environment comfortable through cooling, ventilation and heating our spaces; second, to power the appliances that we have come to depend on such as home appliances, lighting systems, computers and other office equipments [3]. To reduce this high percentage of energy use and the resultant carbon dioxide emissions, both sources of energy use in buildings must be addressed [4].

This short paper will aim to shed light on some of these developments on the medal east use Al Aqaba residence energy efficiency in Jordan as a case study.

Corresponding author: Mayyadah Fahmi Hussein, Dr., assistant professor, research field: interior design. E-mail: mayada19732004@yahoo.com.

\section{Indoor Environmental Quality}

The IEQ (indoor environmental quality) category in building standards, one of the five environmental categories, was created to provide comfort, well-being and productivity of occupants. The IEQ category addresses design and construction guidelines especially: IAQ (indoor air quality), thermal quality, and lighting quality indoor air quality seeks to reduce VOC (volatile organic compounds), and other air impurities such as microbial contaminants. Buildings rely on a properly designed HVAC (heating, ventilation, and air-conditioning) system to provide adequate ventilation and air filtration as well as isolate operations (kitchens, dry cleaners, etc.) from other occupancies [5]. During the design and construction process, choosing construction materials and interior finish products with zero or low emissions will improve IAQ. Many building materials and cleaning/maintenance products emit toxic gases, such as VOC's and formaldehyde. These gases can have a detrimental impact on occupants' health and 
productivity as well. Avoiding these products will increase a building's IEQ [6].

Personal temperature and airflow control over the HVAC system coupled with a properly designed building envelope will also aid in increasing a building's thermal quality. Creating a high performance luminous environment through the careful integration of natural and artificial light sources will improve on the lighting quality of a structure [7].

\section{Requirements of the Indoor Environmental Quality Intent in Jordan}

The intent of this prerequisite is to prevent the development of indoor air quality within buildings, thus contributing to the comfort and well-being of the occupants [8,9], as shown in Fig. 1.

\section{The Analysis of the Indoor Environmental Requirements in AREE Aqaba Residence Energy Efficiency}

In this paragraph, we will discuss the use of the

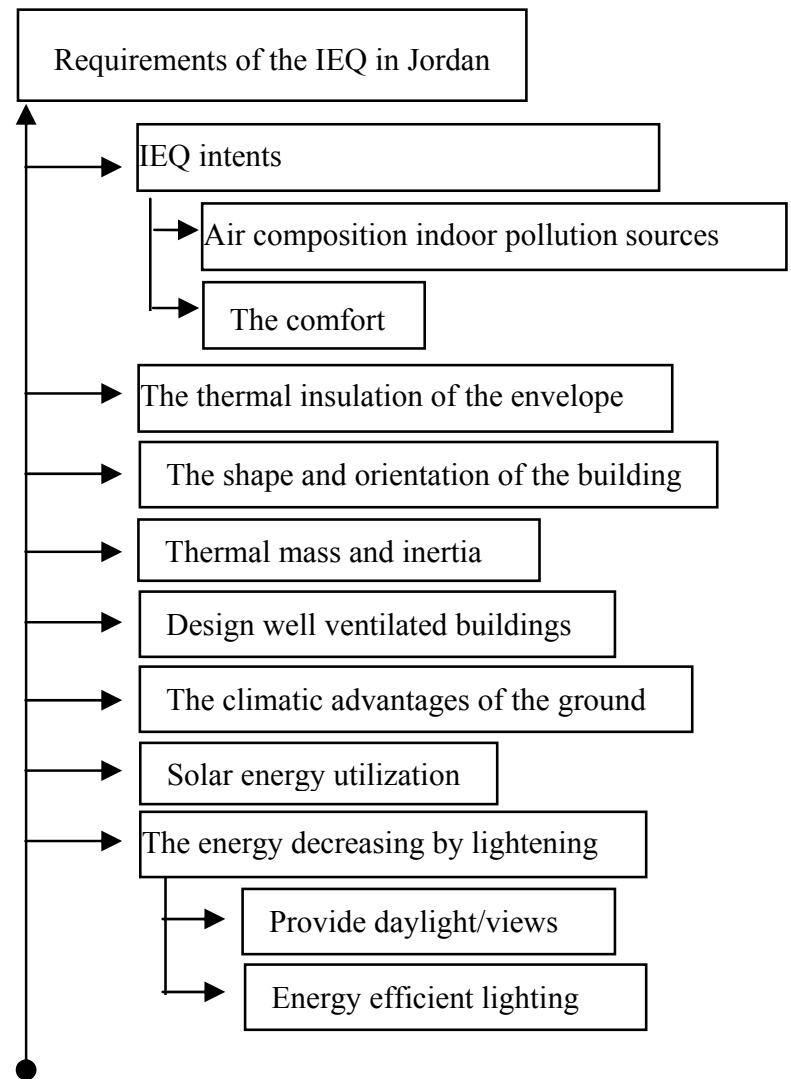

Fig. 1 Requirements of the IEQ in Jordan. criteria required for the indoor environmental requirements in green building in Jordan, by using descriptive analytical approach in one case study ( $\mathrm{Al}$ Aqaba Residence) AREE, and analyze the uses of its requirements in the indoor environmental quality.

The AREE (Aqaba residence energy efficiency) project [10] is an environmentally-friendly pilot project built in Aqaba's 9th District. The building accommodates $420 \mathrm{~m}^{2}$ of residential space. This project encourages better design and construction practices that promote passive and active energy efficiency, water efficiency and environmentally friendly construction materials and techniques. One of the main purposes of the project is to demonstrate the cost effectiveness of energy efficient design, construction techniques and installations for a typical residential building, particularly in a hot, dry climate.

The AREE building was selected by the EU-funded MED ENEC2 project as one of 10 pilot projects that aim at promoting energy efficiency in buildings in the Mediterranean region.

\subsection{The Shape and Orientation of the Building}

\subsubsection{Orientation}

The design aimed at orienting the long sides of the building masses along an east-west axis so that its long sides would face north and south. Southern exposures provide the optimum solution in terms of maximizing the sun's rays. However, the shape of the land plot and existing zoning regulations in that area did not allow for a true southern exposure, as shown in Figs. 2 and 3 [10].

\subsubsection{Layout}

The development of floor plans carefully placed the house's different functions in order to save as much heating and cooling energy as possible, service rooms and areas such as the garage on the ground floor and the corridors on the first and second floors. In Fig. 4, it is placed in the zones most susceptible to heat gain during the summer. This way, they serve as buffer zones for internal rooms. They do not need to be cooled or heated since they are only transitional spaces through which people pass, but do not stay in for long periods [10]. 


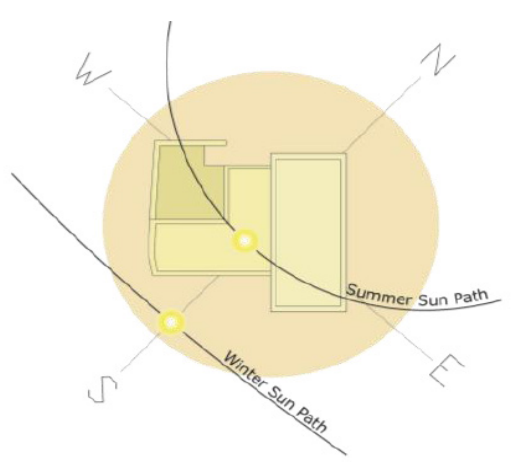

Horizontal sun path

Fig. 2 AREE's orientation in comparison to the horizontal sun's angles [10].

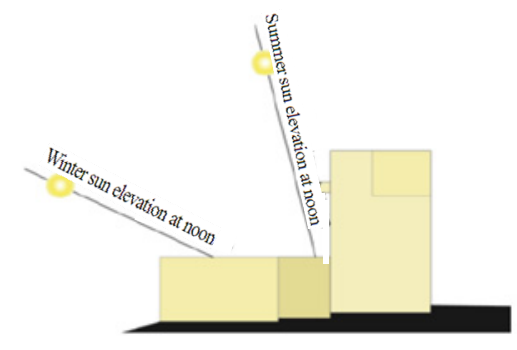

Vertical Sun Angles

Fig. 3 AREEs orientation in comparison to vertical sun's angles [10].

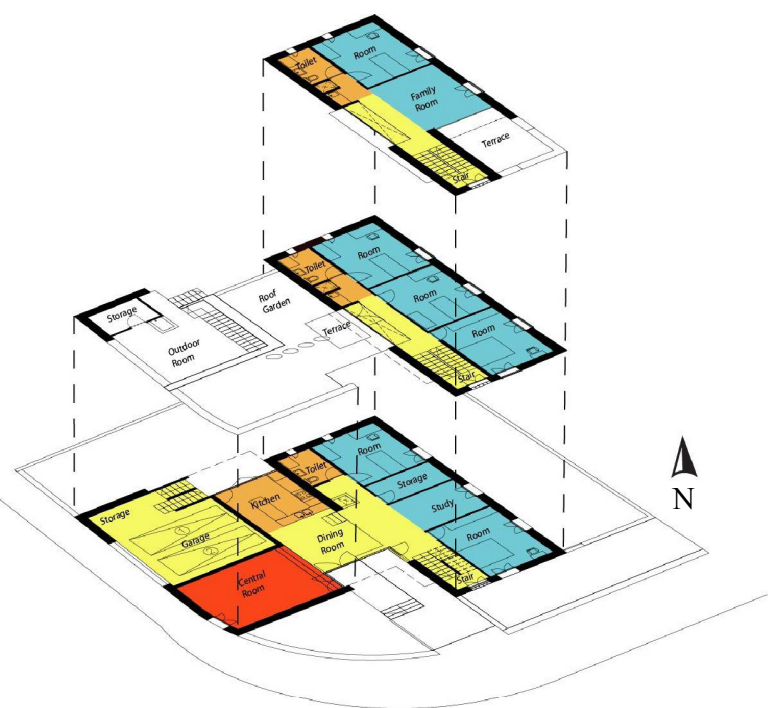

Fig. 4 Layout plan of AREE's three floors [10].

\subsection{Ventilation System in AREE}

The ground floor in Fig. 5 shows how openings were carefully placed opposite each other to maximize the effects of cross ventilation. This also applies within the rooms themselves, where windows and doors are placed opposite each other. Even if the doors and windows of the rooms are closed for privacy, both the internal doors and external windows are designed to include small openings at their top to maintain cross ventilation. Within the house, openings were generally provided along opposite elevations. The placement of openings was also thought of within the context of the house's different levels. The staircase was placed in a way that allows it to function as a wind tower. It, together with the double height corridor space on that extends across the first and second floors, allow the hot air in the house to rise and thus create a vertical hot air draft, thus improving natural ventilation in the house. The design takes advantage of the fact that hot air rises over cool air. For that reason, a set of small windows were placed at the top of the staircase to induce the upward movement of hot air and direct it outside the building, as shown in Figs. 5 and 6 [10].

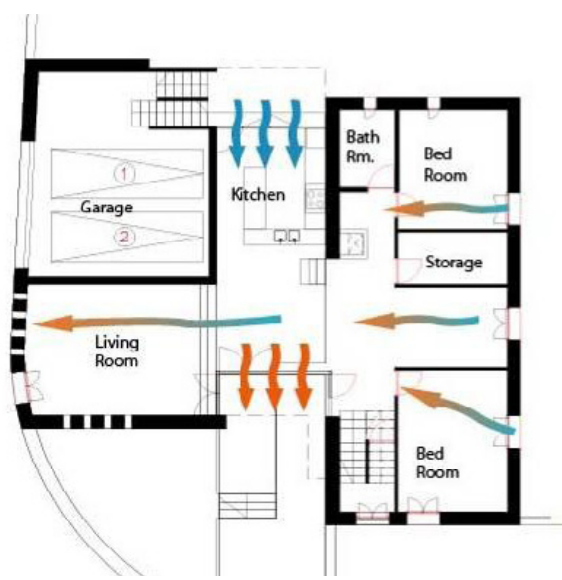

Fig. 5 Ground floor plan showing the induced cross ventilation [10].

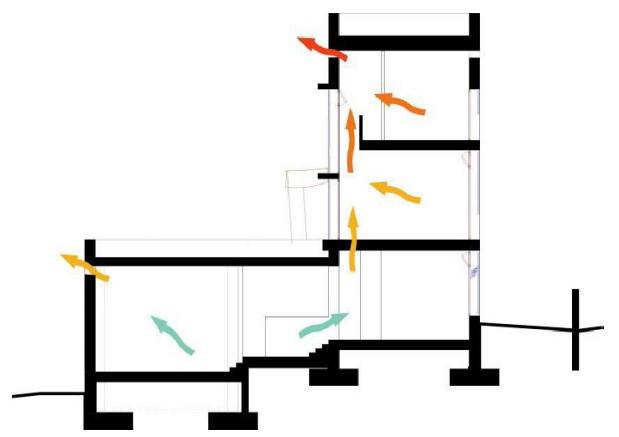

Fig. 6 Section showing how the hot air rises and exits the house [10]. 
On the ground floor, the cool northern wind is captured from the kitchen entrance, and is further cooled by a small water pool underneath the kitchen entrance, as shown in Fig. 7.

\subsection{The Thermal, Visual, Acoustic Comfort in AREE}

The design incorporates elements that help contribute to the energy efficiency of the house, and enhance indoor thermal, acoustic and visual comfort.

About shading elements, the design incorporates movable and fixed shading elements that are used to shade the walls and windows. The shading of external walls helps prevent the absorption of heat into the building mass, while movable external shading of windows prevents direct sunlight from entering into the building during the summer at the times when the sun angle is low "in the afternoon for example". The followings are several types of shading that have been used for this building: horizontal cantilevers, external vertical sliding shades for windows, fixed decorative open concrete blocks in front of the eastern staircase window that allow for air movement yet prevent direct sunlight from entering, fixed shading structures for the outdoor spaces and in front of large windows such as

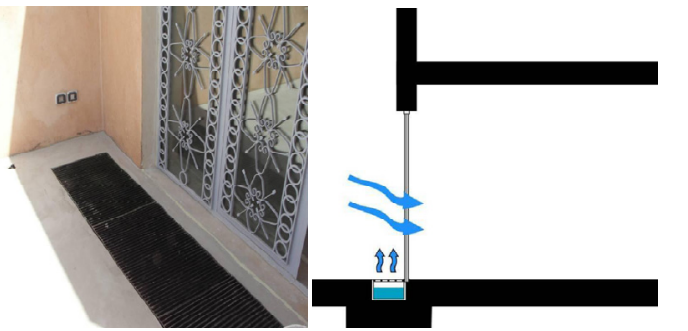

(a)

(b)

Fig. 7 Section (a) and image (b) showing the evaporative pool and its cooling effect on the air that enters the kitchen door [10].

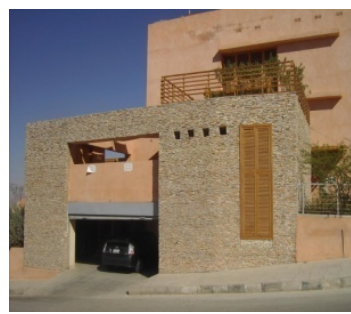

(a)

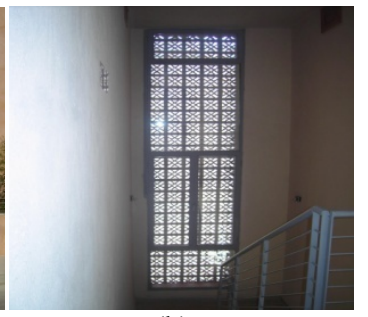

(b)
Fig. 8 Images of different shading elements used in the building to shade external walls (a) and openings (b). the kitchen and dining area windows, as shown in Fig. 8.

\subsection{Furniture}

Producing 100\% environmentally friendly local furniture cannot be obtained in Jordan today. Because demand by consumers for environmental furniture is extremely low, it is very hard to find suppliers who are interested in providing eco-friendly materials for making furniture.

Furthermore, furniture manufacturers do not have clear regulations regarding their working environment. Toxic fumes and residues often are released during the manufacturing process through the use of varnishes and adhesives that contain formaldehyde, which can be harmful to both workers and the environment.

\subsection{Thermal Mass and Inertia}

Narrow vertical windows were used throughout the building. The shaded narrow windows allow little direct sunlight to enter during the hot months, while the glazed area is just large enough to allow natural daylight to enter deep into the rooms during the day. Windows are located along the building's northern and southern sides, whereas eastern and western windows are avoided because they allow the hot sun to enter during the summer days. When it was necessary to use them, they were made extremely small in size.

\subsection{The Thermal Insulation of AREE}

Green roofs, walls with translucent insulation, and materials with high thermal characteristics are not well known in the usual practice.

\subsubsection{Roof Insulation of AREE}

A $5 \mathrm{~cm}$ insulating layer was applied to the roofs' construction. A layer of stabilized sand mixed with a small portion of cement was used instead of a concrete screed layer. The sand has lower thermal conductivity and a high thermal mass, which help improve the roof's insulation. Waterproofing the building usually is achieved by using bitumen sheets. However, bitumen sheets cannot be installed on top of the insulation. They, 
therefore, were substituted for polyethylene sheets, which is sufficient in Aqaba, where average annual rainfall is only $30 \mathrm{~mm}$. As mentioned earlier, part of the roof was used as a roof garden.

The only exception to the use of small and narrow windows is a big glazed window that runs over two stories along the southern facade. This glazed area serves as a sun collector during the winter, while a wooden lattice shades it in the summer, preventing direct sunlight to enter. The extra layer of soil on top of the roof increases its thermal mass and helps offset heat gain. The plants on the roof garden and the solar heating panels also shade the roof, as shown in Fig. 9.

\subsubsection{Green Roof}

Here, the ground cover Carpobrptus Edulis is particularly effective, completely covering the soil after only one year. Steppingstones allow for easier maintenance. Nerium oleander and Agave give height and also color as they bloom. Nerium oleander is intended to grow and density quickly, thus providing the patio with shade and privacy from the street.

These plants were planted in a soil mixture of sand, tuf stone, and local yellow and red soil with some clay content. The soil surface was covered with tuf to control water evaporation. Tuf also provides for an aesthetically pleasing ground cove (Fig. 10).

\subsection{Walls and Wall Materials}

\subsubsection{Wall Types}

The typical wall formation in Jordan basically consists

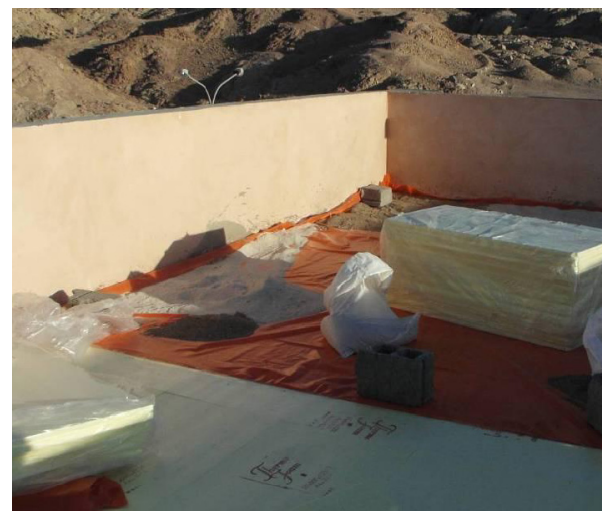

Fig. 9 The polyethylene sheets spread over the roof the landscaping of the roof garden [10].

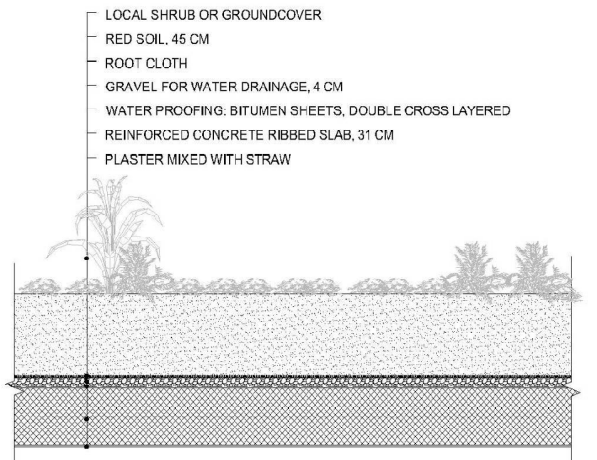

Fig. 10 Section showing the construction detail for the roof garden $[10]$.

(from the inside out) of a $10 \mathrm{~cm}$ plastered hollow cement block wall, $5 \mathrm{~cm}$ of insulation, and a $7 \mathrm{~cm}$ stone cladding attached to a $7-10 \mathrm{~cm}$ concrete layer.

The building's structural design aimed at upgrading conventional wall sections and experimenting with new ideas, keeping in mind the use of locally produced materials as much as possible. Three different wall sections were used in the building's construction:

Wall 1-Hollow concrete block cavity wall with plaster finish mixed with straw. The cavity is filled with Rockwool for insulation, as well as sand and straw to increase the thermal capacity (thermal mass) of the walls.

Wall 2-Hollow concrete block cavity wall with Rockwool for insulation and a plaster finish mixed with straw (Total $U$-value $=0.39 \mathrm{~W} / \mathrm{M}^{2} \mathrm{~K}$;

Wall 3-Cavity wall with stone cladding on one side and plaster finish on the other (Total $U$-value $=0.50$ $\left.\mathrm{W} / \mathrm{M}^{2} \mathrm{~K}\right)$.

\subsubsection{Concrete Blocks}

Three different types of concrete blocks were examined to choose the best sustainable option:

Type 1: Hollow blocks made with perlite aggregate (from Greece), $U$-value $=2.00 \mathrm{~W} / \mathrm{M}^{2} \mathrm{~K}$;

Type 2: Hollow blocks made with volcanic aggregate (from Mafraq, Jordan), $U$-value $=3.13$ $\mathrm{W} / \mathrm{M}^{2} \mathrm{~K}$

Type 3: Typical hollow blocks (made in Jordan, and available in most Jordanian markets), $U$-value $=5.55$ $\mathrm{W} / \mathrm{M}^{2} \mathrm{~K}$.

After comparing the three types, Type 1 was found 
to have the least $U$-value, followed by Type 2 . Type 1 , however, has a large amount of latent energy embedded in it since the aggregate has to be imported, and thus includes considerable energy consumption needed for shipping and transportation. For this reason, Type 2 was chosen. Soon after construction was initiated, there was a shortage of Type 2 blocks in the market. This forced the construction team to use Type 1 instead (Fig. 11).

\subsubsection{Masonry}

Stone cladding is typical in external wall construction in Jordan. The stone used in the construction of the building consisted of stone scrap and leftovers collected from stone workshops. This choice was asked on the need to minimize the environmental impact of stone quarries and to show that recycled materials can have an aesthetic value. The result is a beautiful façade with a collage of different stone colors. The un-wanted leftover material initially was obtained for free. However, once the workshop providing the stones learned that their waste was used as a construction material, they started charging for it (Fig. 12).

Stone was used on the southern facade as well as for a few of the internal walls at the ground floor level. The high thermal capacity of the stone helps offset heat gain during the day and radiates it at night, when the temperatures are cooler.

\subsubsection{Plaster}

Plaster was mixed with straw and pigment as an

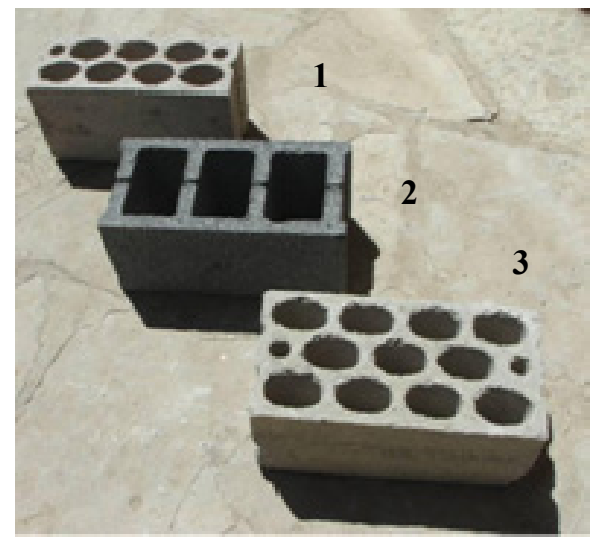

Fig. 11 Image showing the three concrete block types mentioned above.

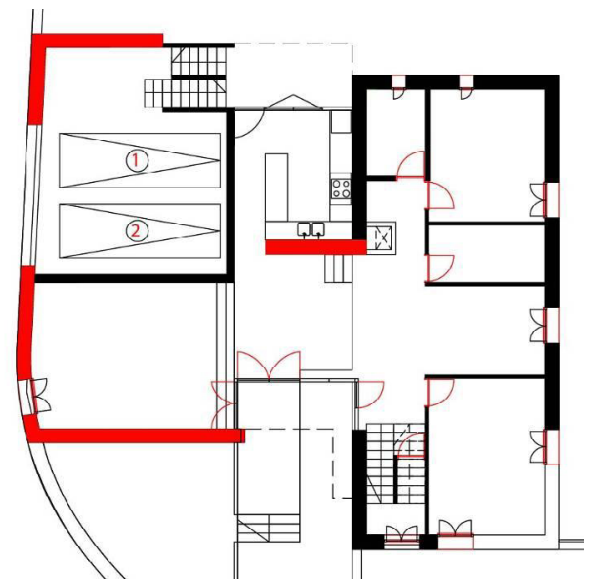

Fig. 12 Image of an internal stone wall, and the ground floor plan showing the location of stone walls (in gray).

experiment aimed at decreasing the $U$-value of the conventional plaster finish made solely from cement and then covered with paint. By adding straw to the plaster mixture, the amount of needed cement decreases by $25 \%$, and the $U$-value for the plaster is improved by $400 \%$. However, since the thickness of the plaster on the wall is very small, this addition of the straw to the mixture has little impact on the wall's total $U$-value. Yet, the straw gives a nice aging quality to the wall, and the addition of the pigment to the mixture reduces the labor costs resulting from adding yet another coat of paint on top of the plaster.

\subsection{Wall Insulation}

Rockwool, polystyrene and a sand-straw mixture were used for insulation within the walls. The last challenge affecting insulation involved wet construction. The conventional wall construction process in Jordan starts with building the internal block wall first, followed by applying the insulation, building a few rows of stone, and then pouring the concrete backing between the stone work and the insulation. The pouring of concrete compresses the insulation, thus lowering its insulating capacity, and also may result in breaking the damp proofing material that covers the insulation. A preferred way to construct the wall would be to use wood framing to build the outer layer of the wall, then fixing the insulation to it, after which the internal block wall would be built (Fig. 13). 


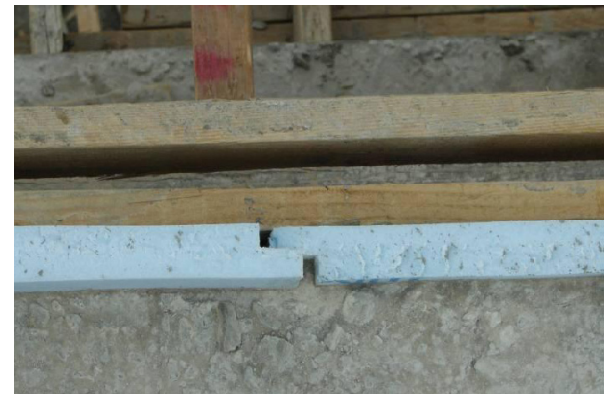

Fig. 13 The overlapping of insulation material to insure equal distribution the house.

\subsection{Windows Insulation}

As mentioned earlier, the building's windows are longitudinal in shape to allow daylight to enter, while minimizing the duration of the sun's penetration through them. The only exception to this rule is the large glazed window on the southern facade of the building, which is intended to function as a heat collector that heats the house during the winter. This window is well shaded during the summer to prevent direct sunlight from entering the building.

All of the windows have external movable wooden shades in order to control direct sunlight as needed.

Windows throughout the building are double glazed. Double glazing in windows lowers their $U$-value from $5.9 \mathrm{~W} / \mathrm{m}^{2} \mathrm{~K}$ to $2.9 \mathrm{~W} / \mathrm{m}^{2} \mathrm{~K}$. Double glazing also decreases the windows transmittance of solar radiation from $83 \%$ to $69 \%$. Large longitudinal windows used in the rooms included a small opening at their upper parts. These windows, together with the windows above the internal room doors, allow constant air flow even when doors and windows are closed. Windows were designed with steel window frames rather than aluminum ones, which require a more involved manufacturing process. Foam strips were used around the steel frames to insure air-tightness. Wooden frames for the movable shading screens also function as insulators for the steel windows. Each window is placed along the internal side of the wall. This maximizes the benefits of the shade provided by the thickness of the building skin (Fig. 14).

\subsection{The Climatic Advantages of the Ground}

The design uses the three different levels of the ground floor offered by the slightly sloping site for installing several subsoil pipes. The subsoil pipes capture the cool air at the building's northern facade and take it underground, where it is further cooled by the subsoil temperatures, and leads them to an outlet in the living room (Fig. 15).

\subsection{PV (Photovoltaic) Systems Cells}

PV systems generally are used as part of a hybrid electricity generating system that is connected to the power grid. PV cells placed on top of a residence can produce more energy than it needs. It, therefore, would be more efficient if the surplus energy can be sold to the electricity provider. In the mean time, the electricity located in the power grid would be needed at times when solar energy is not sufficient for the house, such as during nighttime or when there is cloud cover (Fig. 16).

4.11.1 Domestic Hot Water Supply

During the summer in Aqaba, there is hardly any need for water heating. In the winter, domestic hot water is supplied by a system of panels that collect solar energy to heat the water. The system is composed of 11 Azuro Paradigma panels, each with 24 evacuated tubes. These solar collectors are placed on the main roof. Each panel is $2 \mathrm{~m} \times 1.6 \mathrm{~m}$ in cross sectional area, and occupies a roof area of $2 \mathrm{~m} \times$ $1.50 \mathrm{~m}$. There are three rows of panels. One row of five

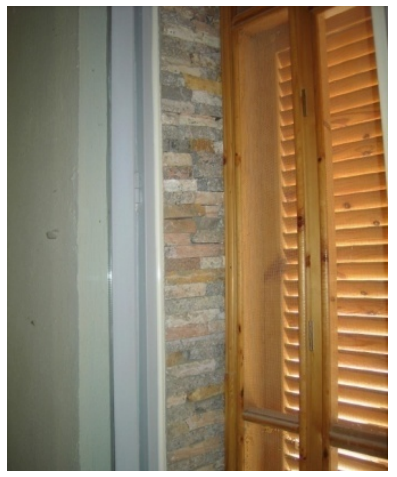

Fig. 14 Many types of the windows inside the house. 


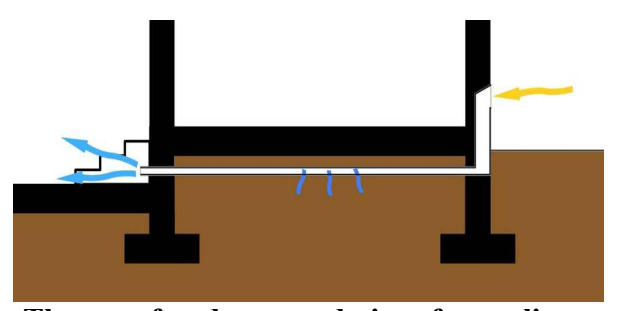

Fig. 15 The use of underground pipes for cooling.

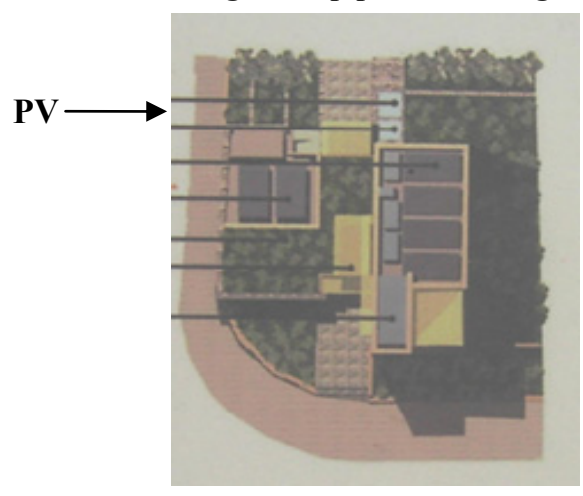

Fig. 16 PV systems in AEER.

collectors faces the southeast, and is tilted at an angle of six degrees. Each of the other two rows of three collectors faces the southwest, and is tilted at an angle of 17 degrees. This is to maximize the benefit of solar energy throughout the year. The collectors are placed in a manner so as not to shade each other during the summer or winter, and also to provide maintenance space in between. The total area that the collectors occupy is about $32 \mathrm{~m}^{2}$.

In order to prevent overheating, the collector fields have pressure valves that feed back into the hot water tank, and also a heat dissipater with an outlet to the roof floor.

\subsubsection{Heating System}

Thermal modeling of the building design showed that there was hardly a need for heating. Therefore, no heating system has been installed. In case of extreme cold winters in Aqaba, heating may be provided using movable gas heaters (residential air).

\subsubsection{Cooling System}

The strong sun of Aqaba is available throughout the year, and it is the best energy source to use, even for cooling purposes. The building features an experimental solar adsorptive cooling system in order to utilize the abundantly available solar energy for cooling purposes. The amount of solar energy that be collected during the hot summer months exceed what is needed by the solar cooling system.

\subsection{Energy Efficient Fixtures}

\subsubsection{Lighting}

Outdoor lighting: The lighting concept for the building is based on color change with LED lights (Philips LED line 2). The mixing of RGV colors makes it possible to create almost any given lighting color.

Indoor lighting: The controls allow lights on the window side of the room to adjust automatically as the amount of daylight in a space decreases or increases, all without disturbing the occupants. This solution ensures comfortable lighting levels. The application of this system results in substantial energy savings at the window side (up to $70 \%$ ), and it can always be switched off when the spaces are not in use.

\subsubsection{Electrical Appliances}

The building owner tried to choose the most energy efficient appliances available in the market. There is no standard rating system for energy performance for electrical appliances in Jordan, although some appliances have European ratings placed on them.

\section{Conclusions}

Prohibit smoking in the building and around building entrances, operable windows, and air intakes.

Ensure adequate ventilation: Appropriately size and operate ventilation systems to supply ample outside air to the occupants. Follow the directory of green buildings in Jordan.

Monitor carbon dioxide: Install monitors and integrate them with a ventilation system that regulates the supply of air based on occupant demand.

Install high-efficiency air filters: Use filters with high MERV (minimum efficiency reporting value) ratings in the ventilation equipment.

A successful daylighting design not only optimizes architectural features, but is also integrated with the 


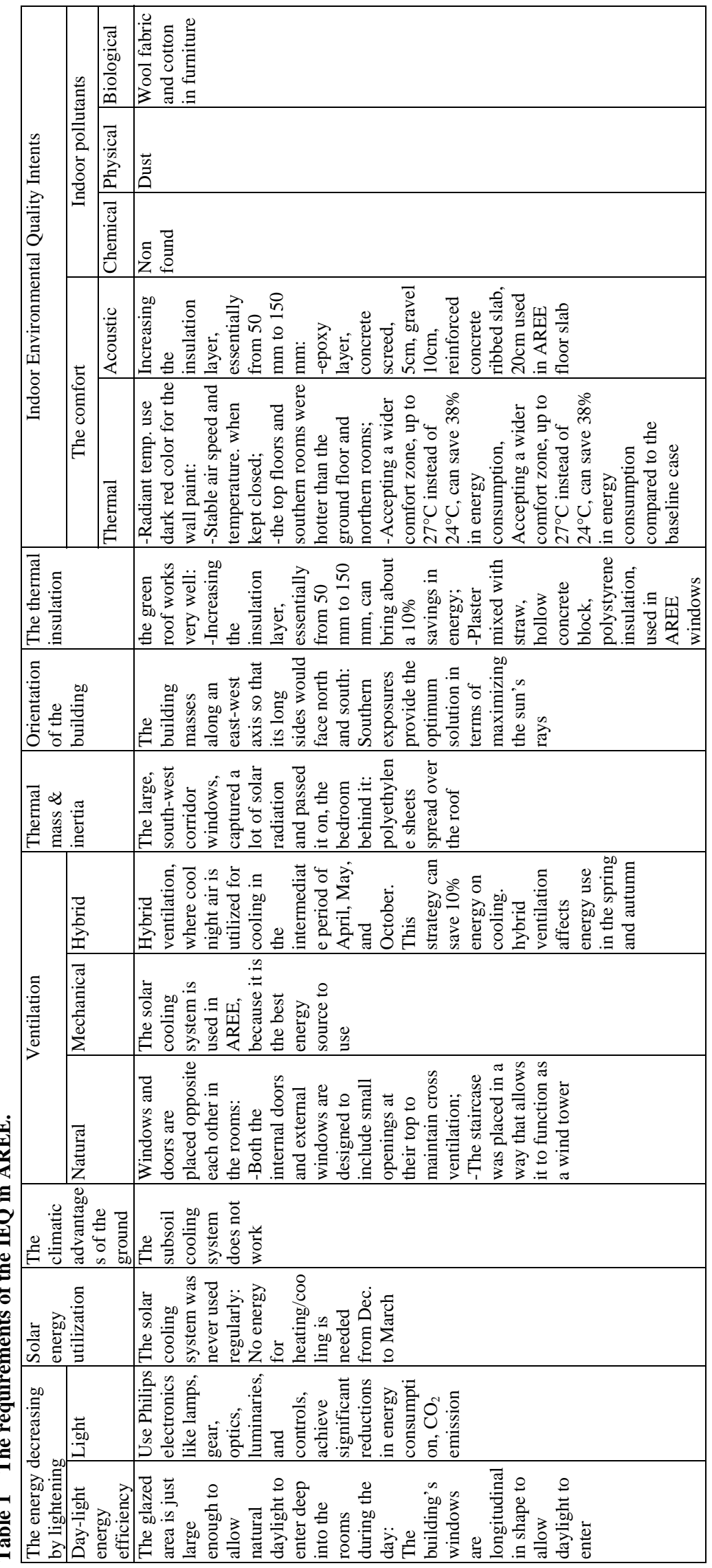


Table 2 The positive effects of the indoor environmental indoor quality requires.

\begin{tabular}{|c|c|c|c|c|c|c|}
\hline Requirement name & West & Energy & Water & Ecosystem & Emission $\mathrm{CO}_{2}$ Pollution & Comfort \\
\hline IEQ intents & - & - & - & - & - & $*$ \\
\hline Control of environmental tobacco smoke & - & $*$ & - & $*$ & $*$ & * \\
\hline Control of chemicals contaminants & - & - & * & - & * & * \\
\hline Design well ventilated buildings & - & - & - & - & - & * \\
\hline Provide daylight/views & - & $*$ & - & - & - & $*$ \\
\hline Energy efficient lighting & - & - & - & - & - & * \\
\hline Thermal comfort & - & * & - & $*$ & $*$ & $*$ \\
\hline Consider acoustics & - & - & - & - & - & $*$ \\
\hline
\end{tabular}

- means non-use.

electric lighting system. With advanced lighting controls, it is now possible to adjust the level of electric light when sufficient daylight is available. Three types of controls are commercially available in Jordan like: witching controls, stepped controls and dimming controls. As shown in Table 1, the requirements of the indoor environmentally quality in AREE, and in Table 2, the positive effects of the indoor environmental indoor quality requires. Architectural and constructive solutions and the way of use.

Buildings that consume a high quantity of energy for mechanical ventilation, but it is not paid attention to the moisture, occupation degree or noise protection. On the other hand, the buildings with low energy consumption, natural ventilated, present a healthy and comfortable inside environment.

Specify low-emitting materials. Use green materials for both new construction and renovations.

Select cleaning products and technologies to minimize the introduction of contaminants and reduce the use of pesticides and other potentially toxic contaminants.

\section{References}

[1] I. Bliuc, R. Rotberg, L. Dumitrescu, Simulation and performance analysis of hydrothermal behavior of buildings in transient regime, in: Proceedings of the
International Conference on Performance Based Engineering for 21st Century, Cemi lasi, 2004, pp. 43-48.

[2] I. Bliuc, R. Rotberg, The impact of some dwelling energy-Efficiency raising measures on the inner environment quality, in: Evaluation Methodology on CISBAT Conference, Lansanne, 2005, pp. 55-65.

[3] Directory of Green Buildings in Jordan, Ministry of Works and Public, Amman, Jordan, 2010, pp. 169-212.

[4] Y.S. Lee, D.A. Guerin, Indoor environmental quality differences between office types in LEED-certified buildings in the US, Building and Environment 7 (2) (2009) 293-300.

[5] Residential Air System Design, Heating Refrigerating and Air-Conditioning Institute of Canada HRAI, Islington, 1986, pp. 21-33.

[6] C.A. Roulet, B. Ostra, F. Foradini, C.H. Cox, Designing healthy, comfortable and energy efficient buildings: Lessons from enquiries within the European Hope project, in: Evaluation Methodology on CISBAT Conference, Lansanne, 2005, pp. 173-189.

[7] C.A. Roulet, B. Ostra, F. Foradini, C. Cox, Designing healthy, comfortable and efficient buildings: Lessons from enquiries within the European energy HOPE Project, in: Evaluation Methodology on CISBAT Conference, Lausanne, 2005, pp. 48-58.

[8] F. Visser, M. Al-Asad, AREE (Aqaba Residence Energy Efficiency), The Complete Experience, The Center for the Study of the Built Environment CSBE, Jordan, 2011, pp. 6-36.

[9] Green Building Basics Web Site, http://www.ciwmb. ca.gov/GREENBUILDING/basics.htm (accessed Jan. 23, 2008).

[10] The Jordon Building, http://www.carboun.com/tag/jordan (accessed Mar. 25, 2007). 